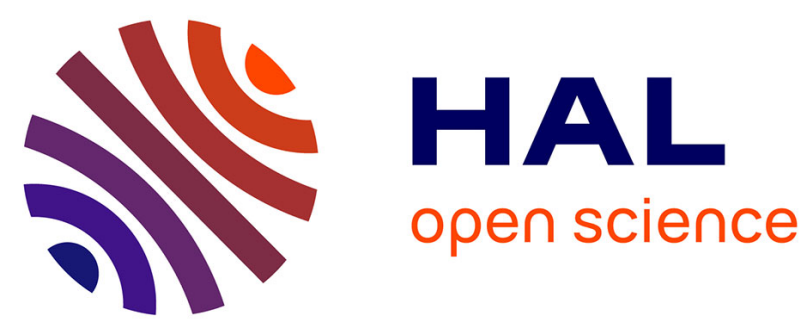

\title{
STRUCTURE OF THE SILICIDE/Si, SiO2/Si INTERFACE ANALYSED USING HIGH RESOLUTION TRANSMISSION ELECTRON MICROSCOPY
}

C. d'Anterroches, Pascal Perret, J. Brosselin

\section{- To cite this version:}

C. d'Anterroches, Pascal Perret, J. Brosselin. STRUCTURE OF THE SILICIDE/Si, SiO2/Si INTERFACE ANALYSED USING HIGH RESOLUTION TRANSMISSION ELECTRON MICROSCOPY. Journal de Physique Colloques, 1990, 51 (C1), pp.C1-729-C1-736. 10.1051/jphyscol:19901116 . jpa00230024

\section{HAL Id: jpa-00230024 https://hal.science/jpa-00230024}

Submitted on 1 Jan 1990

HAL is a multi-disciplinary open access archive for the deposit and dissemination of scientific research documents, whether they are published or not. The documents may come from teaching and research institutions in France or abroad, or from public or private research centers.
L'archive ouverte pluridisciplinaire HAL, est destinée au dépôt et à la diffusion de documents scientifiques de niveau recherche, publiés ou non, émanant des établissements d'enseignement et de recherche français ou étrangers, des laboratoires publics ou privés. 


\title{
STRUCTURE OF THE SILICIDE/Si, $\mathrm{SiO}_{2} / \mathrm{Si}$ INTERFACE ANALYSED USING HIGH RESOLUTION TRANSMISSION ELECTRON MICROSCOPY
}

\author{
C. D'ANTERROCHES, P. PERRET and J.R. BROSSELIN \\ CNET-CNS-BP. 98, Chemin du Vieux chêne, F-38243 Meylan Cedex, France
}

\begin{abstract}
This paper is a kind of over- view of the problems which have to be solved in order to determine an interface structure.

The first question is to be able to interpret the micrographs knowing that the dynamical interaction between electron wave and atomic potential is highly dependent on the crystal structure. Differences between centrosymmetric and non-centrosymmetyric crystals are underlined.
\end{abstract}

The example which is treated is $\mathrm{ErSi}_{2}$, and the $\mathrm{ErSi}_{2} / \mathrm{Si}$ interface is analysed.

The second problem is the thickness variation at the interface vicinity ; this is shown to imply contrast variations which can be interpreted as the presence of a thin film between the substrate and the over layer.

Finally it is shown how high resolution images are a necessary complement to determine microcrystallite structures, when they are $100 \mathrm{few}$ and small to be analysed using $\mathrm{X}$-Ray diffraction. The example is $\mathrm{SiO}_{2}$ precipitates grown in amorphous $\mathrm{SiO}_{2}$ during ultra dry oxidation.

\section{I - INTRODUCTION}

Over the last few years interface structures have been increasingly studied. The first interfaces to be analysed were tilt boundaries as the crystals have a common axis parallel to the interface. This axis can be aligned with the electron beam. Thus, there is no superimposition of the atomic potential of each crystal and good High Resolution Transmission Electron Microscopy (HREM) images can be obtained $(1,2,3,4)$; this is the best case. In the case of interfaces between different materials, if both of them are ordered crystals, many conditions must be satisfied in order to obtain good images. First they must have a common axis. Furthermore since the contrast in the image depends on the specimen thickness and the defocusing distance, the domain in which a good projection of the atomic potential is obtained is very limited. Moreover, the right domain must coincide for both crystals. The difficulty is that the greater the difference in the structure of the crystals, the smaller the domain $(5,6,7)$. Besides, in order to interpret the images, image simulations must be performed. The method of simulation requires the thickness of both crystals to be the same. Experimentally it is often difficult to obtain such a thinning of the specimen.

The mathematical development for the contrast in the image will be given elsewhere, and thus only the application to $\mathrm{ErSi}_{2}$ will be treated here. The simulated images closest to the projected potential will be shown. These will be given for two crystal orientations.

The difficulties encountered in obtaining good images of interfaces will be detailed and the determination of interface structure will be applied to the $\mathrm{ErSi}_{2} / \mathrm{Si}$ interface.

Thus, this first part of the paper will show that the crystal structure must be known in order to simulate images and thus be able to interpret HREM images. The second part will explain how HREM can be a complement in the determination of a crystal structure when the latter is unknown. The example of the new crystalline $\mathrm{SiO}_{2}$ phase will be taken.

All the HREM and simulated images will be given for a $400 \mathrm{KV}$ Jeol 4000 EX electron microscope.

\section{II - CONTRAST INTERPRETATION}

Many years ago $O$. Scherzer (8) demonstrated that the focusing, illumination and aperture conditions can change the limit of resolution by a factor of about 3 . He calculated the 
defocusing distance such that the transfer function of the microscope is maximum for a large interval of frequencies. High resolution images are usually taken under these conditions because this defocusing distance is easily identified during the experiment by following the contrast of amorphous material. Although images taken under these conditions are close to the projected potential of some crystals such as Silicon (9) it is not always the case, because usually the crystal behaviour is far from weak phase object. As an example, Figure 1 shows a simulated image of a $5 \mathrm{~nm}$ thick $\mathrm{ErSi}_{2}$ sample at the Scherzer defocusing distance. In this image it can be seen that the spots do not strictly correspond to the projection of atomic columns, and other conditions have thus to be determined.
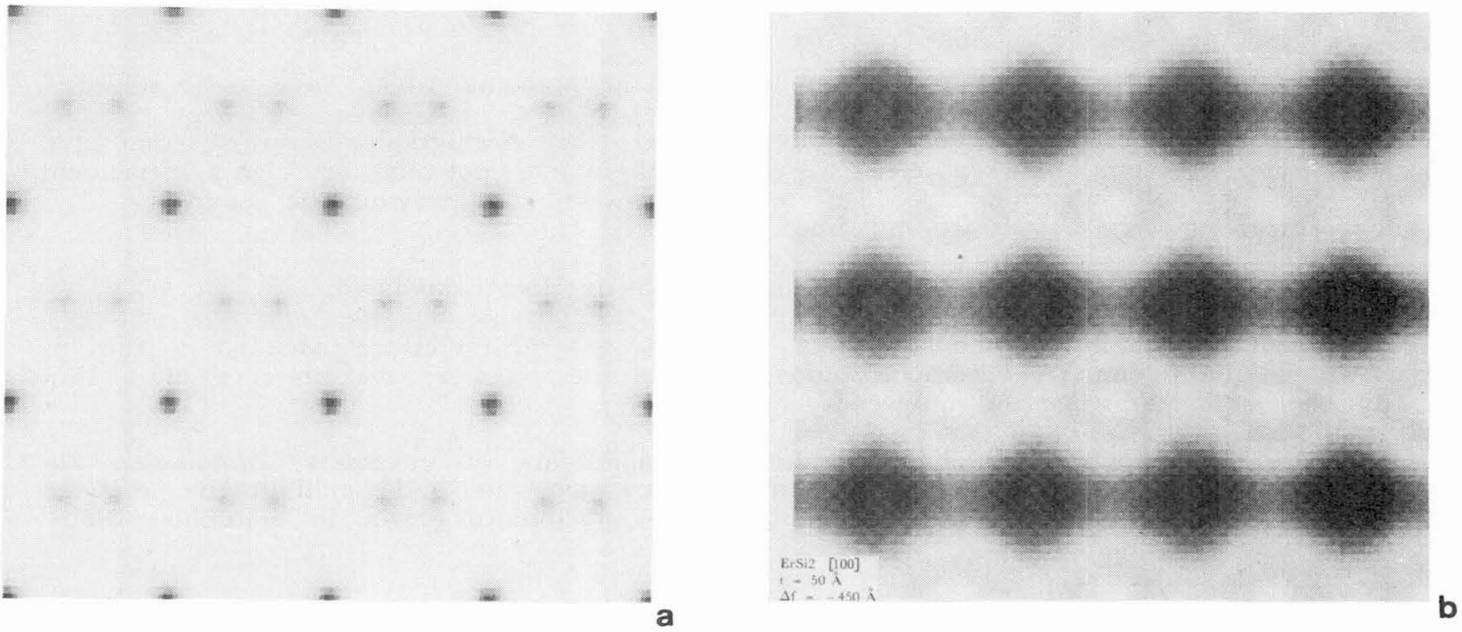

Fig. 1 - Image simulation of $\mathrm{ErSi}_{2}$; [1010] zone axis ; near Scherzer defocusing distance. - a - Projected potential. Erbium is black, Silicon is grey.

- $\mathrm{b}$ - Image $\mathrm{t}=5 \mathrm{~nm}, \Delta \mathrm{f}=-45 \mathrm{~nm}$. The dots do not correspond to the projected potential.

Considering the wave function at the exit surface of the specimen, it is a linear combination of plane waves over the vectors of the reciprocal space. It will be shown elsewhere (10) that, in the domains of strong image intensities for the principal diffracted beams, the resulting intensity is the sum of intensities for each beam. This applies also to beams diffracted by a non-centrosymmetric crystal, but only if the difference in amplitude for opposing diffracted beams is negligible.

The maximum intensity can correspond either to the atomic column projection, or to the holes in the structure; these two cases will be named respectively $T=+1$ or $T=-1$. In the intermediate case $T=0$, the image does not correspond to the projection of atomic potential.

If the electron beam is aligned with the [1010] zone axis of $\mathrm{ErSi}_{2}$, six beams are preponderant for $5 \mathrm{~nm}$ thick crystals. They are $(1,0)(0,1)(2,0)$ and their opposites. The maximum difference in amplitude for these beams is $0.1 \%$ and can thus be considered negligible. Hence, the approximation described above applies. The problem is that there are no thickness $(t)$ and defocusing distance $(\Delta f)$ domains such that the sign of $T$ is the same for all beams. The best area is $-45 \mathrm{~nm}<\Delta \mathrm{f}<-53 \mathrm{~nm}$ and $\mathrm{t} \simeq 2 \mathrm{~nm}$, where $T \sim-1$ for $(1,0),(0,1)$ and $(2,0)$, but the specimen is too thin to obtain good HREM images. For higher thicknesses and the same defocusing distance, for example $t=5 \mathrm{~nm}, T \sim 0$ for (1, $0)$ its contribution is therefore not representative of the structure, but its intensity is lower than that provided by beams $(0,1)$ and $(2,0)$. Thus, as seen in Figure 2, the dark spots correspond to the projection of atomic columns i.e. the so-called negative contrast. But the intensity is not minimum on the Erbium positions because the contrast is $T=0$ for $(1,0)$. Moreover there are no domains for which projection of atomic columns is bright (i.e. so-called positive contrast).

On the other hand, in the case of [1100] illumination, the only image representative of the projected potential is a positive contrast. It is obtained in the following domain $-55 \mathrm{~nm}<\Delta \mathrm{f}<-65 \mathrm{~nm} 5 \mathrm{~nm}<\mathrm{t}<10 \mathrm{~nm}$, and the corresponding image is shown in Figure $3 \mathrm{a}$. Figure $3 \mathrm{~b}$ shows that under the same conditions, the silicon contrast is not of the same kind. 

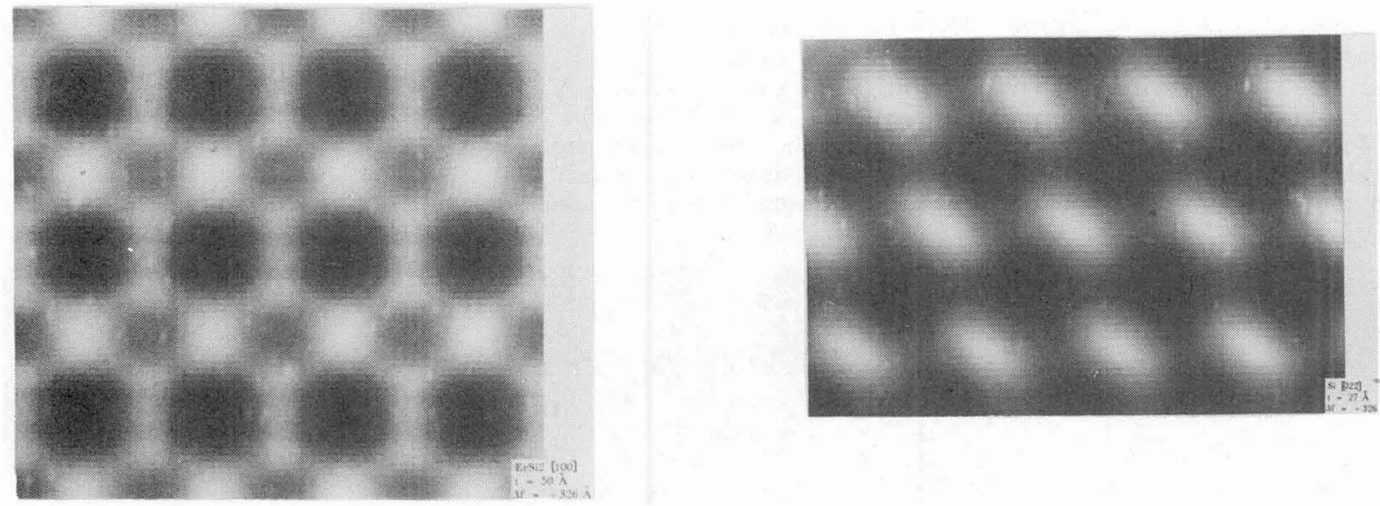

Fig. 2 - Image simulation.

- a - ErSin ; [10̄0] zone axis ; $t=5 \mathrm{~nm}, \Delta \mathrm{f}=-33 \mathrm{~nm}$.

$-\mathrm{b}-\mathrm{Si} ;$ foil] zone axis ; $\mathrm{t}=5 \mathrm{~nm}, \Delta \mathrm{f}=-33 \mathrm{~nm}$.
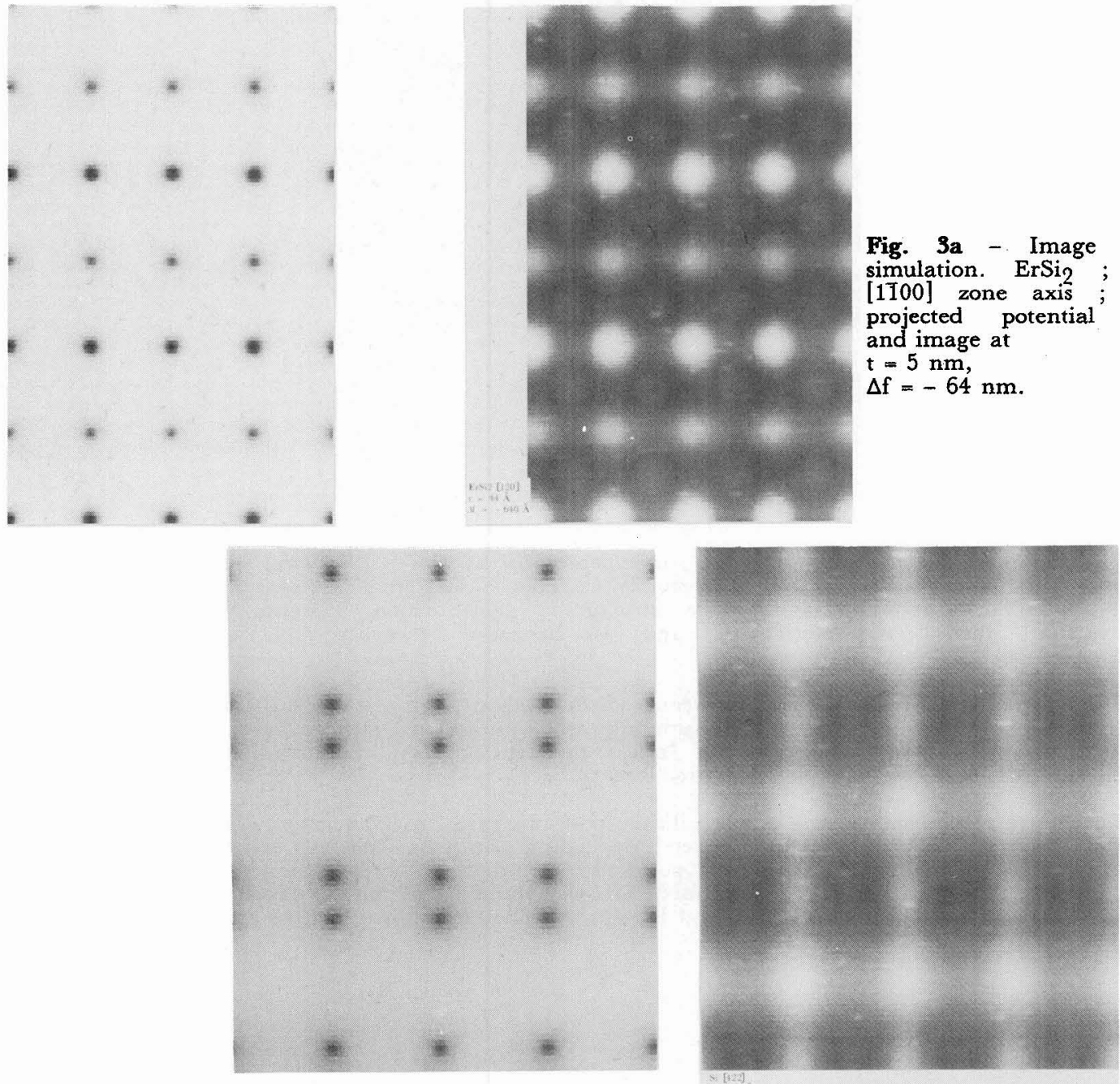

Fig. 3b - Image simulation. Si $\mathrm{t}=5 \mathrm{~nm}, \Delta \mathrm{f}=-64 \mathrm{~nm}$. 


\section{III - - INTERFACE STRUCTURE DETERMINATION}

The above discussion shows that the interface structure between two different materials is usually not directly interpretable. In the case of the $\mathrm{ErSi}_{2} / \mathrm{Si}$ interface observation under [1010] illumination of $\mathrm{ErSi}_{2}$, the silicon crystal is under [220] illumination. Moreover in the domain of negative contrast for $\mathrm{ErSi}_{2}$, the contrast is also negative for silicon (cf. Fig. 2). Unfortunately, although the image (shown in Figure 4a) is easily interpretable, it is difficult to localise the interface plane; is it plane I or plane II ? Thus, images taken at other defocusing distances have to be considered.

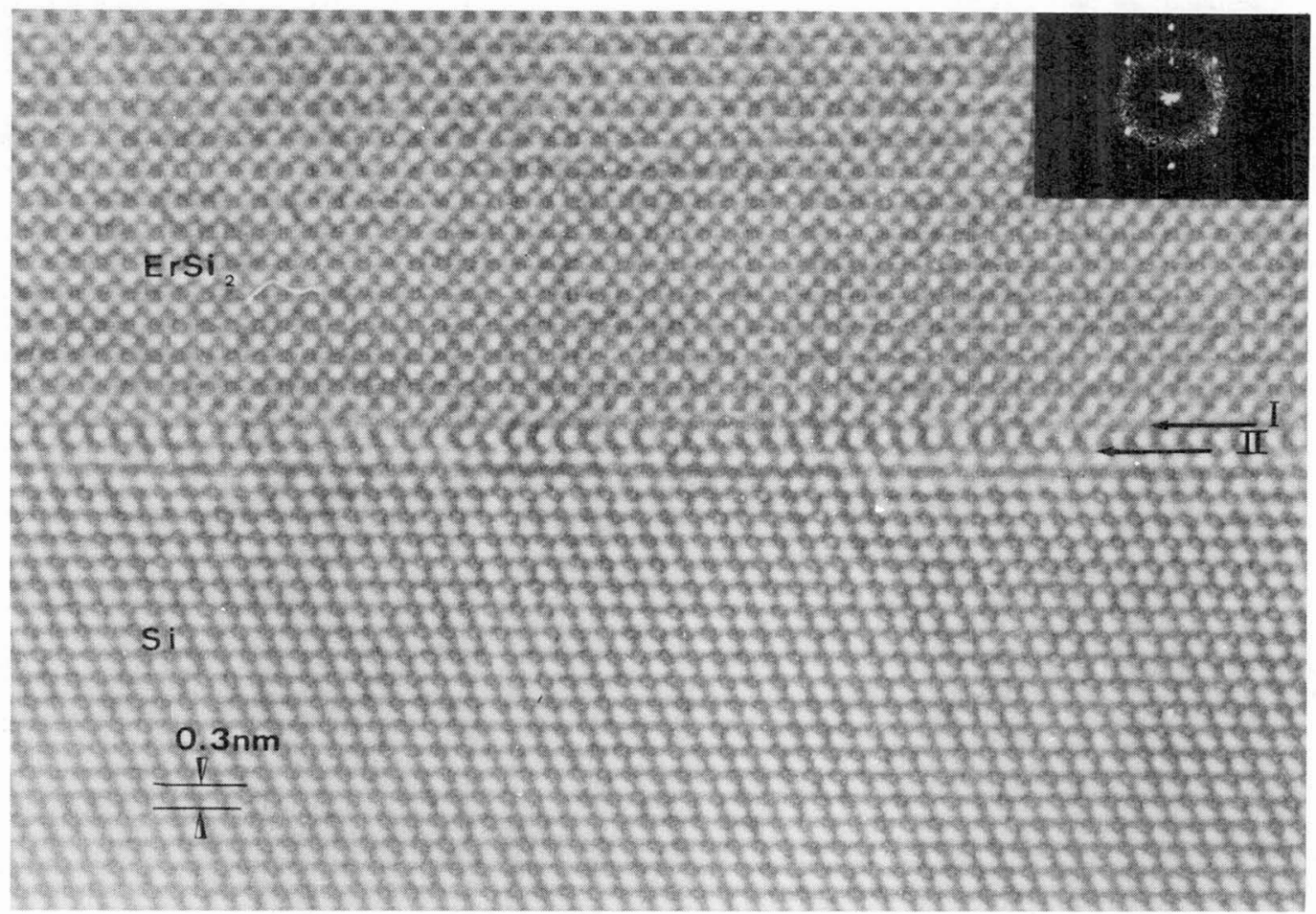

Fig. $4 \mathrm{a}-\mathrm{ErSi}_{2} / \mathrm{Si}(111)$ interface ; [011]Si zone axis HREM image. $\mathrm{t}=5 \mathrm{~nm}$; $\Delta \mathrm{f}=-33 \mathrm{~nm}$.

The example shown in Figure $4 \mathrm{~b}$ corresponds to $\Delta \mathrm{f}=-100 \mathrm{~nm}$, and in this case the interface plane is very easily detectable. This shows that a defocusing series is needed in order to interpret an interface structure. From such a series the $\mathrm{ErSi}_{2} / \mathrm{Si}_{\mathrm{S}} \mathrm{interface}$ structure has been determined, and is described elsewhere (11), it will be shortly depicted now.

The epitaxial relationship between $\mathrm{ErSi}_{2}$ and $\mathrm{Si}$ is $(12 \overline{3} 0) \mathrm{ErSi}_{2} / /(022) \mathrm{Si}$ and $(10 \overline{1}) \mathrm{ErSi}_{2} / /(422) \mathrm{Si}$. Thus, considering the projected lattices along (022)Si, according to the concept of coincidence site lattice proposed by W. Bollmann (13), eight models for the interface structure have been deduced.

There are four planes in which silicon positions are in coincidence, named I, II, III and IV. That leads to eight models depending on the silicon which is present at the interface. Model $a$, the silicon positions are that of bulk silicon, model $b$, the silicon positions are that of silicon in bulk $\mathrm{ErSi}_{2}$. From the relative positions of $\mathrm{ErSi}_{2}$ and $\mathrm{Si}$ we deduced that only models Ia, Ib and IIb apply. They are shown in Figure 5. 


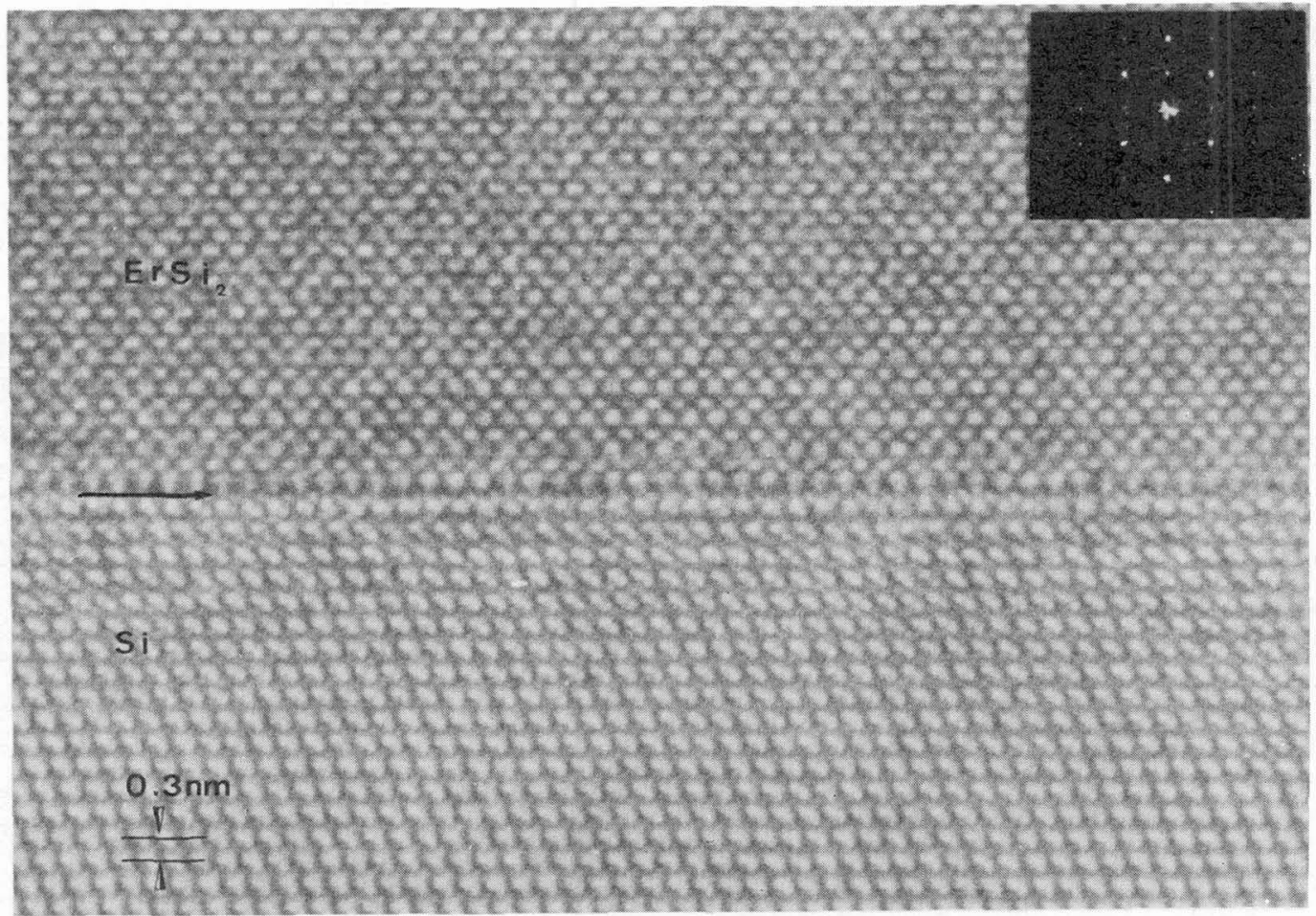

. 4b - [011]Si zone axis HREM image. $33 \mathrm{~nm} . \mathrm{t}=5 \mathrm{~nm} ; \Delta \mathrm{f}=-100 \mathrm{~nm}$.

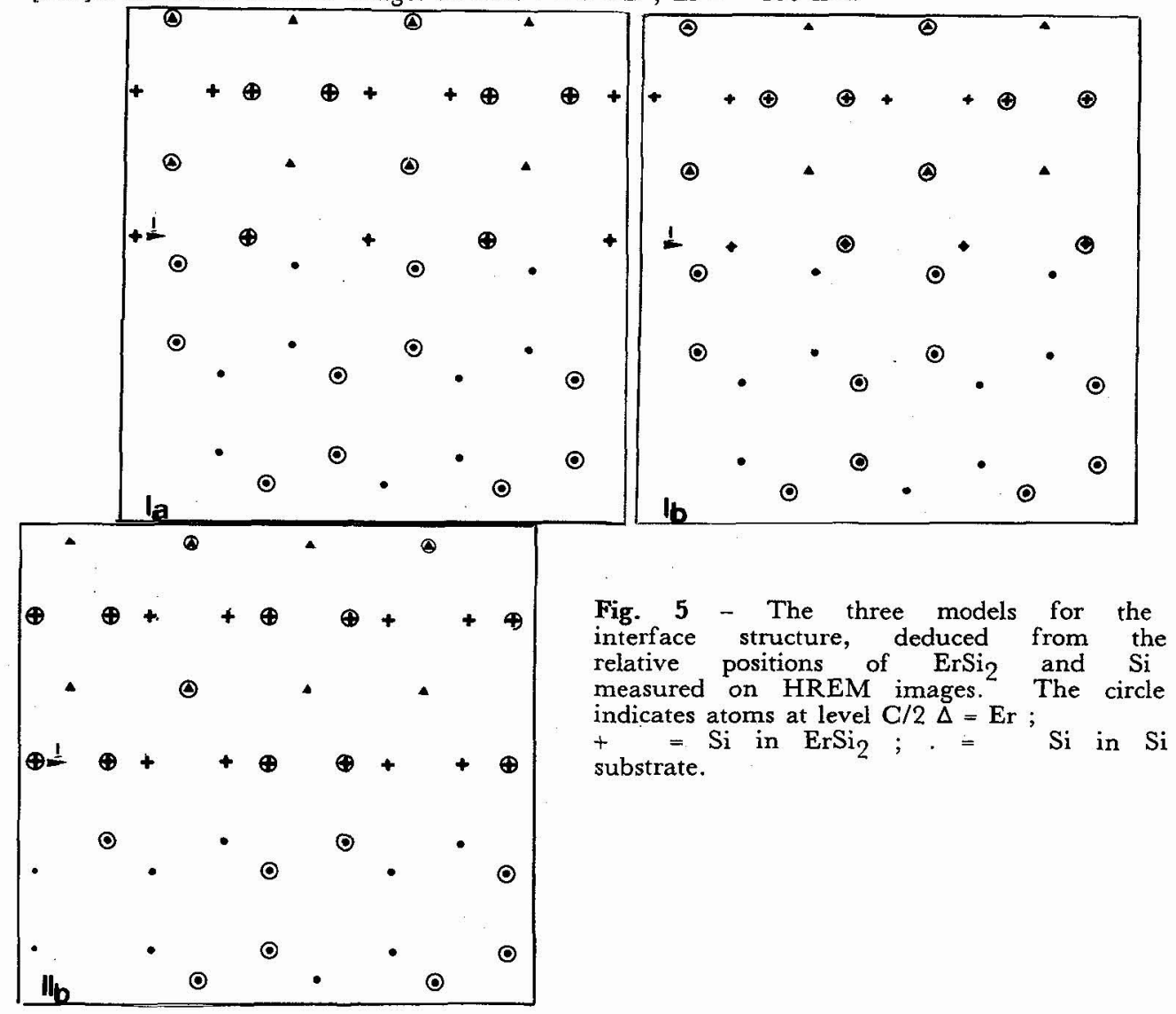


Models Ia and $\mathrm{Ib}$ correspond to the same interface plane thus only a comparison between image simultation and HREM image allows the determination of the interface structure. In figure 6 this comparison is shown at thickness and defocusing distance such that the difference in the contrast for both models is the highest. It is clear that model Ia is the only representative of the structure. This is a result of great interest because it shows that, at the $\mathrm{ErSi} / \mathrm{Si}$ interface, the silicon atomic positions are either that they are in bulk silicon (model Ia) or that they are in bulk ErSin (model IIb). The limits of the observed areas in the HREM mode do not allow to determine the proportion of each structure at the interface. But it is sure that the electrical properties come from these two kinds of bounds.

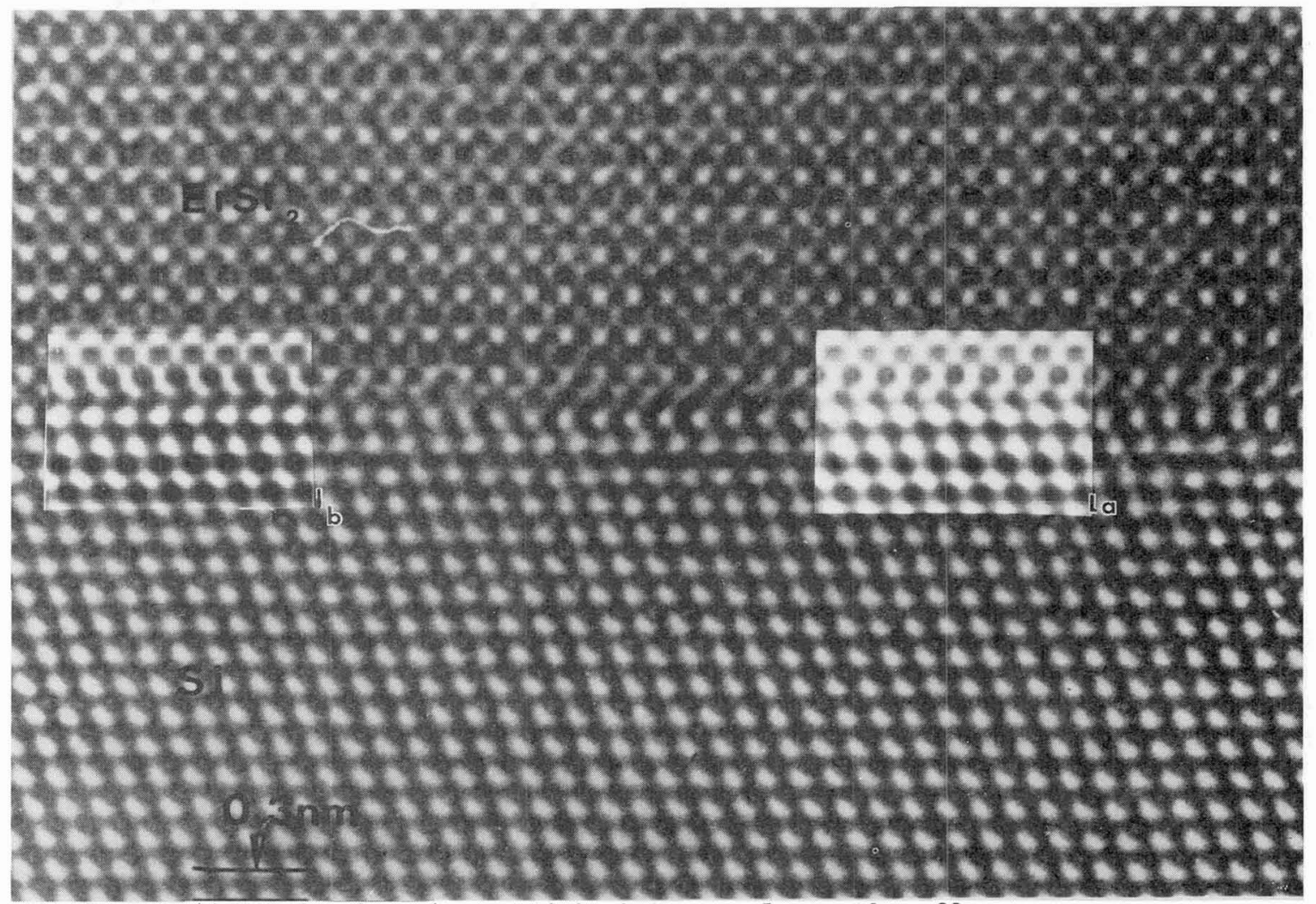

Fig. $6-\mathrm{ErSi}_{2} / \mathrm{si}(111)$ interface ; image and simulation : $\mathrm{t}=5 \mathrm{~mm}, \Delta \mathrm{f}=-33 \mathrm{~nm}$

Another problem to avoid in determining an interface structure is a change in the material thickness at the vicinity of the interface.

The contrast in the image depends both on the defocusing distance and the specimen thickness (9). When the contrast is half-way between negative and positive the image is not representative of the projected potential. Indeed, in the case of a centrosymmetric crystal, the double period appears (9), and in the case of a non-centrosymmetric crystal the double period and a combination of all periods appear (10). Thus, if a change in the specimen thickness occurs, at the interface, the contrast variation can be interpreted as the presence of an intermediate structure. An example is given in Figure $7 \mathrm{a}$ where an area of this kind has been found at the $\mathrm{FeSi}_{2} / \mathrm{Si}$ interface. One can see that, if the image is directly interpreted as an atomic projection, the periodicity is not the same at the interface as elsewhere. The hypothesis of an intermediate film can eventually be eliminated by taking images at various defocusing distances. Indeed, in the case of an artefact there are defocusing distances such that the contrast is the same for small thickness variations. This is shown in Figure $7 \mathrm{~b}$, where there is no contrast change in the vicinity of the interface.

This phenomenon is really critical, as this case cannot be simulated. Indeed, the principle of the calculation of the wave function is that the potential is projected onto an infinitely thin slice and then propagated in the vacuum over a distance $\Delta z$. These sequences are repeated until the real specimen thickness is reached (this is the multislice approximation). Thus, it does not allow a thickness variation over the crystal represented by the first projected potential. 

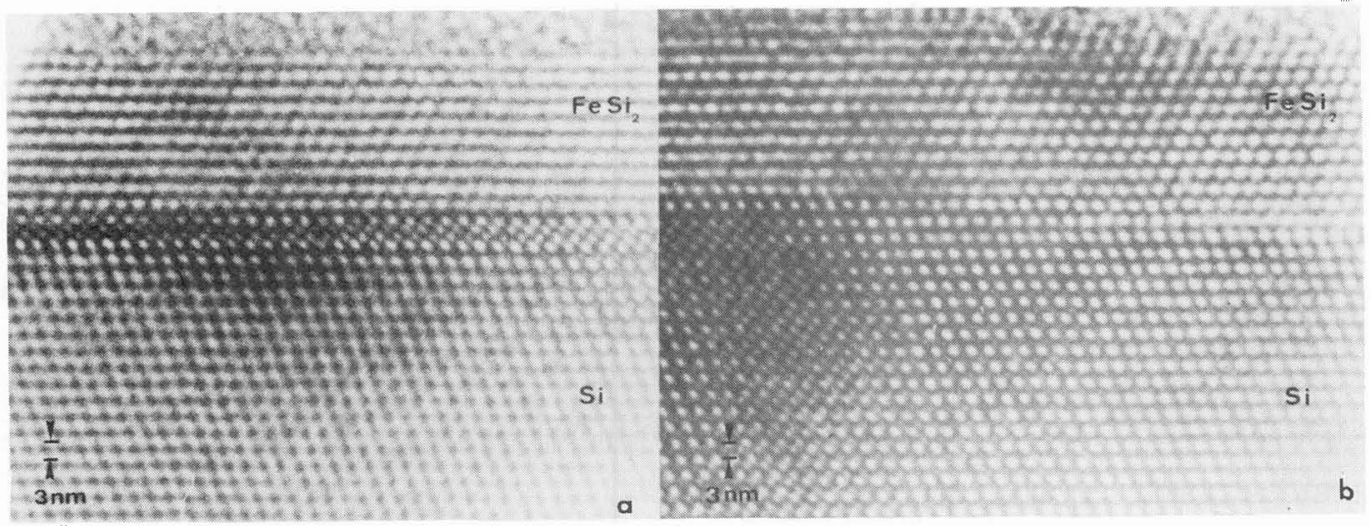

Fig. 7 - FeSi $2 / \mathrm{Si}$ HREM images in the same area.

- a - The double periodicity appears at the interface due to thickness variations.

- b - Image close to the projected potential.

\section{IV - UNKNOWN STRUCTURE}

These considerations raise the problem of an unknown structure. What can be deduced from the HREM images? A priori nothing can be said, and this technique must be taken as a complement to other techniques. This has been illustrated by the analysis of crystallites obtained in an amorphous $\mathrm{SiO}_{2}$ layer under highly dry oxidation (12). These precipitates have been characterized using ultra violet photoemisson (UPS), to determine their composition, and reflection electron diffraction (RHEED), to establish their lattice constants. In this case, HREM images have shown an epitaxial relationship related to the substrate. Certain periodicities obtained by RHEED have been recognized. UPS results have shown that these were $\mathrm{SiO}_{2}$ precipitates. Thus, from images, similar to that presented in Figure 8 we have deduced that it could be strained cristobalite. Confirmation will be given by image simulations and structure factor calculations.

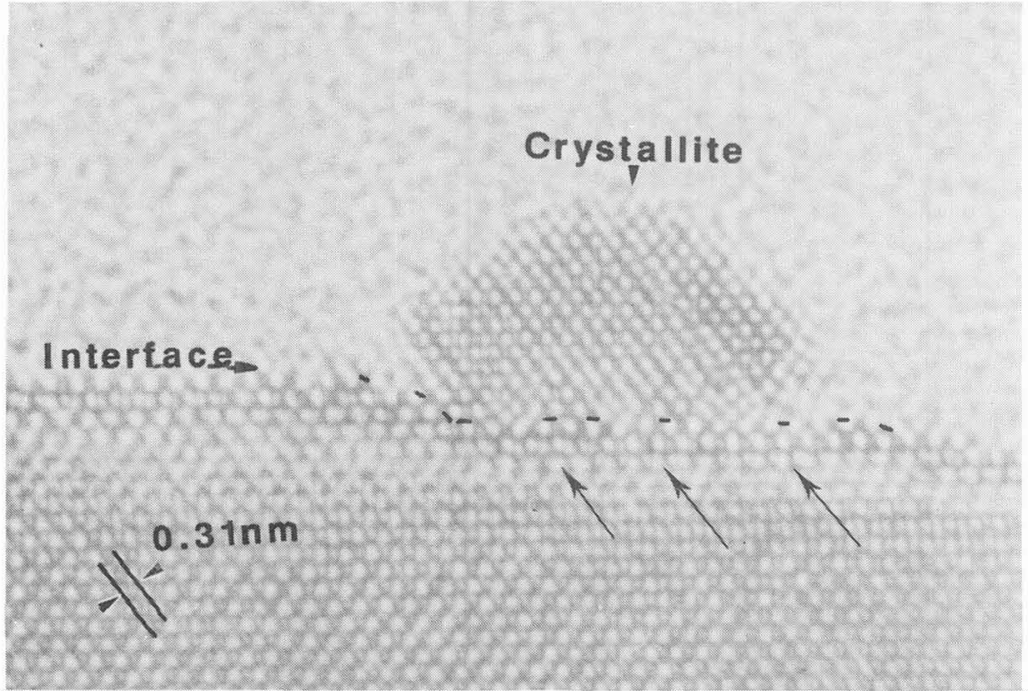

Fig. 8 - HREM image of an $\mathrm{SiO}_{2}$ crystallite grown on Silicon and the associated simulated image. 


\section{V - GONCLUSION}

The object of this paper was not to detail one interface structure but to bring to light the difficulties encountered when such a characterisation is needed.

The differences between images obtained from various materials depending on whether they are centrosymmetric or not have been enhanced, showing that a direct interpretation of the images is usually impossible. The example has been the $\mathrm{ErSi}_{2} / \mathrm{Si}$ interface.

The problem of thickness variations has been underlined on images of $\mathrm{FeSi} / \mathrm{Si}$ interfaces. It has been shown that, as it is impossible to simulate such images, images taken at various defocusing distances must be obtained.

Finally, the question of unknown structure has been raised. It has been shown that the HREM technique cannot be used alone in order to determine a structure.

\section{REFERENCES}

/1/ Krivanek, O.L., Isoda, S. and Kobayashi, K., Phil. Mag. 36 (1977) 931.

12 Bourret, A. and d'Anterroches, C., 37th Ann. Proc. Elec. Micros. Soc. Amer. (1979) 388.

13/ Ichinose, H. and Ishida, Y., Philos. Mag. A 43 (1981) 1253.

14/ Ruhle, M., J. de Phys. C6 (1982) 115.

15/ Cherns, D., Anstis, G.R., Hutchison, J.L. and Spence, J.C.H., Philos. Mag. A 49 (1984) 849 .

16/ d'Anterroches, G. and Arnaud d'Avitaya, F., Thin Solid Films 137 (1986) 351

17/ Kawarada, H., Ishida, Y., Nakanishi, J,, Ohdomari, I. and Horiuchi, S., Philos. Mag. A 54 (1986) 729 .

18/ Scherzer, O., J. of App. Phys. 20 (1949) 20.

19/ Desseaux, J., Renault, A. and Bourret, A., Phil. Mag. 35 (1977) $357 .$.

/10/ d'Anterroches; C., unpublished work.

/11/ d'Anterroches, C., Perret, P., Arnaud d'Avitaya, F. and Chroboczek, J.A., Proceedings of E.MRS - Strasbourg 30 May (1989).

112/ Rochet, F., Froment, M., d'Anterroches, C., Roulet, H. and Dufour, G., Phil. Mag. B 59, (1989) 339 .

/13/ Bollman, W., Crystal Defects and Crystalline Interfaces, Springer-Verlag (1970). 